\title{
Unlocking Secrets to Healthy Aging among the Elderly within the Joe Gqabi District Municipality, South Africa
}

\author{
Nomalungelo Goduka, Carina Rozani, Collise Njume \\ Indigenous Knowledge Systems Office (IKSO), Walter Sisulu University (WSU), Mthatha, South Africa \\ Email: ngoduka@wsu.ac.za
}

Received May 2014

\begin{abstract}
The search for genetic and environmental factors for longevity is constantly on the rise. While a small proportion of adults gracefully age to 100 years and above, others can barely make it above 50. The Joe Gqabi District Municipality of the Eastern Cape Province in South Africa is one of the few places in the country with a high number of elderly people ( $\geq 80$ years). The purpose of this study was to first identify contributing factors towards longevity in this district. It was secondly to use findings from this study to improve the quality of life that has a potential for the younger generation to experience healthy longer lives. Questionnaires, in-depth interviews, observation and focus group discussions were used to collect data. Results of this study indicated that while environmental factors may influence longevity, genetic factors appear to be the major determinants of long life spans in the Joe Gqabi District Municipality of South Africa. However, more studies to determine the specific genes responsible for longevity will shed more light in the determination of factors that contribute to long life spans in the study area.
\end{abstract}

\section{Keywords}

Longevity, Lifestyle, Genetic Factors, Joe Gqabi, South Africa

\section{Introduction and Background Information}

Successful aging that leads some individuals to become centenarians is no accident. It begins with a meticulously designed interaction between one's genetic make-up and environmental factors. Indicators of environmental influence include the following: diet, healthy living and spirituality. Despite spending much more on healthcare and having better infrastructure than any other African country, life expectancy in South Africa is amongst the lowest in the world [1]. However, pockets of small areas exist such as the Joe Gqabi District Municipality with individuals who live longer than everyone else. It is a rural mountainous area in the Eastern Cape Province which is inhabited by individuals whose lifestyles as they were growing up adhered to indigenous cultural values, diet and work ethics.

The aim of this study was to collect information on genetic factors, healthy living and lifestyle that contribute 
to successful aging. Shared characteristics of the world's longest-lived individuals from three Blue Zones, namely, Sardinia in Italy, Ikaria in Greece and Okinawa in Japan motivated us to conduct this study in the Joe Gqabi District. Another factor that motivated us to conduct this study was, despite the earliest archeological evidence that Africa is the cradle of humanity and civilization no Blue Zones have been established on this continent. Questionnaires, in-depth interviews, observation and focus group discussions were used to collect data. Findings based on this study can be used to provide lessons to younger generations and policy makers for the improvement of the quality of life that has a potential for living healthy and longer within this district, nationally and globally. These findings can also be used to open doors to academic research that will discover more Blue Zones with the longest-lived individuals on the African continent.

The climate in Joe Gqabi is harsh: large temperature fluctuations, unseasonable frost and cold, and relatively low rainfall meaning only less sensitive crops can be grown. Joe Gqabi District Municipality is rural and characterized by a breath taking landscape formed by a range iintaba zoKhahlamba - Drakensberg Mountains that form a boundary between other District Municipalities within South Africa and its neighboring country of Lesotho (Figure 1). The Kraai and the Orange Rivers run from these mountains and meander through the District. The municipalities in the wetter eastern part of the district are mountainous and have communal land as well as commercial farming. The municipalities in the west of the district are flat with Karoo-type vegetation and consist mainly of commercial agriculture, which drives the economy, with extensive farming of sheep and cattle. Subsistence and emerging farmers are to be found in the commercial land areas.

\section{Methods of Research and Data Collection}

Age of participants, number of siblings, offspring, genetic factors, nutrition, lifestyle and spirituality values were recorded. Questionnaires, in-depth interviews, observation and focus group discussions were used to collect data.

\section{Findings and Discussion}

Of the nineteen participants interviewed, 9 were 95 or more years old, 6 of them females. Longevity seems to be associated with genetics in 11 of the 19 cases studied. The diets of 12 of the participants involved the use of indigenous leafy vegetables (ILVs). All participants believed in Christianity. Twelve of them had gardening, walking, and/or doing household activities as daily chores. Only three of the 19 participants did not have children. Human life span is predominantly dependent on genetic and environmental factors [2]. While humans may not be able to control the genetic factors, environmental factors such as nutrition and physical exercise should be well within control. There is no doubt that the food people eat is closely related to their health and life expectancy [3] The results of this study are supportive of this fact, as the majority of participants indicated using indigenous leafy vegetables (ILVs) in their diet (Table 1).

Due to the generally low level of crude fat in many of these vegetables and high levels of total unsaturated fatty acid [4] [5], consumption in large amounts would be beneficial to individuals suffering from overweight or obesity, thereby improving their lifestyle and longevity. The role these plants play in the prevention of premature mortality through prevention of non communicable diseases including cardiovascular diseases (CVD), hypertension, diabetes and cancer can therefore not be underestimated. For this reason, low meat high plantbased dietary patterns are being encouraged to mitigate the hazardous effects of saturated fats in meats to atherogenic/hyper-insulinemic pathologies [6].

Vitamin C, an important dietary component of most vegetables is a free radical scavenger and in addition is able to regenerate other antioxidants such as tocopheroxyl which may play a role in healthy aging and longevity [7]. Different polyphenols employ different mechanisms in the protection of cellular damage and enhance longevity. Some prevent deterioration/damage of cells by oxidation while others reduce cholesterol-production and deposition in the arteries thereby helping to reduce blood pressure [8]. Phyto-components such as catechins (obtained from green teas) and Sulforaphane (from broccoli) are important anti-cancer and anti-CVDs agents respectively.

Being female could be a determining factor of long life span. A total number of 13 out of 19 participants who were 80 years and above were females. Six of the 13 females were 95 years and above compared to only 3 males (Table 1). These findings are consistent in consonance with the reports of Newman and Brach [9], Bobak [10] and Mansdotter [11]. Seventeen of the 19 participants had at least 2 children. While child-bearing may negatively affect longevity due to the stress on the mother and the requirements of upbringing, our study does not 


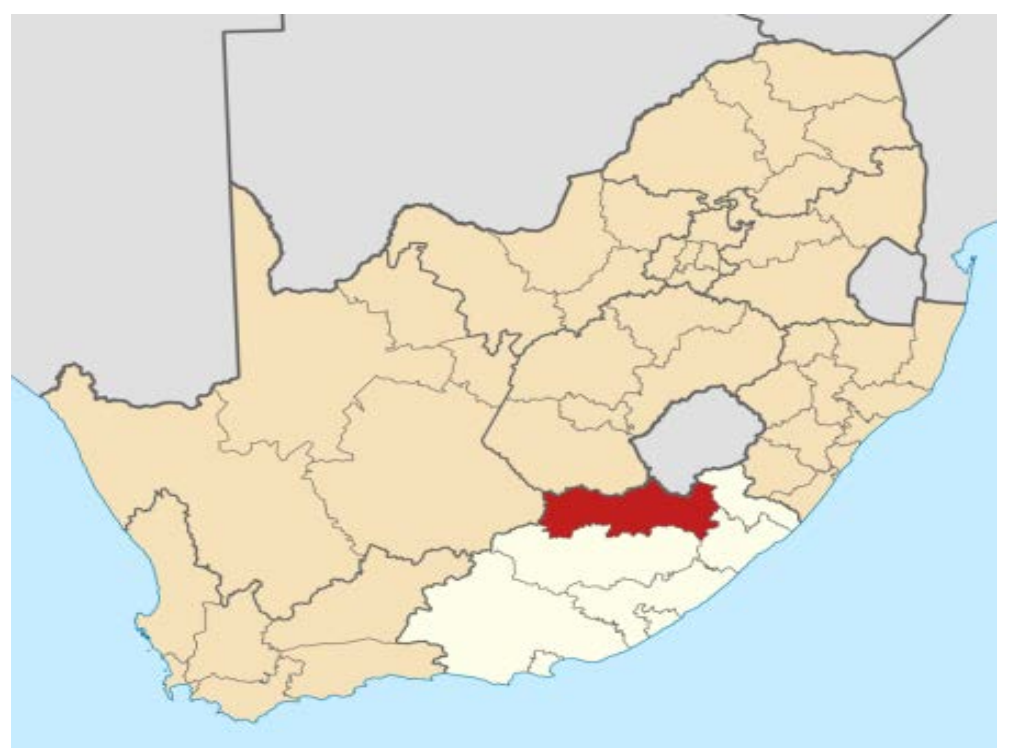

Figure 1. Map of South Africa showing Joe Gqabi District Municipality.

Table 1. Factors likely to be responsible for human longevity in the Joe Gqabi District Municipality of South Africa.

\begin{tabular}{cccccccc}
\hline Participant & Age & Gender & Genetics & Number Offspring & Daily Activity & Diet & Religion \\
\hline NG01 & $80-85$ & M & No & 5 & Gardening, Fencing & Normal & Christian \\
LE02 & $>95$ & F & Yes & 2 & Weeding & Normal, ILVs & Christian \\
MA03 & $80-85$ & F & Yes & 4 & house work & Normal, ILVs & Christian \\
JA04 & $86-90$ & M & Yes & 12 & nothing & Normal, ILVs & Christian \\
MN05 & $>95$ & M & Yes & 12 & Walking, gardening & ILVs mostly & Christian \\
LE06 & $>95$ & F & Yes & - & Walking, gardening & ILVs mostly & Christian \\
MO07 & $80-85$ & F & No & 6 & walking, gardening & Normal, ILVs & Christian \\
KH08 & $80-85$ & F & No & 9 & Gardening, Fencing & Normal, ILVs & Christian \\
HI09 & $>95$ & F & No & 5 & Walking & Normal, ILVs & Christian \\
HE10 & $>95$ & F & No & 5 & Walking and small chores & Normal, ILVs & Christian \\
MO11 & $>95$ & M & Yes & 8 & Gardening, Fencing & ILVs mostly & Christian \\
RA12 & $91-95$ & F & Yes & 5 & House work & Normal & Christian \\
MN13 & $80-85$ & M & Yes & 3 & Walking & Normal & Christian \\
AM14 & $>95$ & F & No & 3 & Cooking & Normal & Christian \\
AO15 & $>95$ & F & No & 6 & grass/clay wks & Normal, ILVs & Christian \\
DZ16 & $86-90$ & F & No & 5 & Physical exercise & ILVs mostly & Christian \\
DZ17 & $80-85$ & F & Yes & 0 & Kitchen wk & Normal, ILVs & Christian \\
NC18 & $91-95$ & F & Yes & 12 & Cooking, walking & Normal & Christian \\
NT19 & $>95$ & M & Yes & 10 & Walking, gardening & Normal & Christian \\
\hline
\end{tabular}

F, Female; M, Male; -, Not determined; ILVs, Indigenous leafy vegetables.

seem to be consistent with this fact. As recorded above, one of the oldest participants had 12 children and many others too (Table 1).

\section{Secrets of Longevity Unlocked at Joe Gqabi through Qualitative Research and Focus Group Discussions}

Eating healthy unprocessed foods earlier in life; e.g. freshly slaughtered stock, (red and white meat, not often too); exercising, i.e. walking and working in the gardening and maize-fields; living by good moral values: 
showing respect towards elders; respect for one's body i.e. not defiling body with pre-marital sex; girls at adolescence not eating highly protein foods like eggs and milk, thus delaying sexual activity; girls not eating lambs that die but leaving that to the boys; boys and young men not engaging in sexual activities consumption of liquor and drugs ;spirituality: showing respect and giving honour to Almighty God and believing that he is the giver of good long healthy lives.

\section{Conclusion}

As the number of elderly people increase in the world, it is good to develop interventions that would contribute to graceful aging and longevity. Genetics have been indentified in this study as a major contributing factor to longevity. However, other factors include gender, spirituality, daily activity and diet. As in many other reports, our results also show that being female tends to be associated with longevity. Normal diet which include vegetables and daily activities like gardening, household chores and walking are all contributing factors to longevity in the Joe Gqabi District Municipality in South Africa.

\section{Acknowledgements}

We are grateful to the Department of Science and Technology (DST), National Research Foundation (NRF), South Africa for funding this study through a grant awarded to the Research Chair for Indigenous Knowledge Systems at Walter Sisulu University. Special thanks to Fr Mafu Ponya, Ms Nkamu Leola and the local community of Joe Gqabi District Municipality for their contribution to this study.

\section{References}

[1] Lehohla, P.J. (2011) Mid-Year Population Estimates. Statistics South Africa, P0302, 1-17.

[2] Kolovou, G., Barzilai, N., Caruso, C., Sikora, E., Capri, M., Tzanetakou, I.P., Bilianou, H., Avery, P., Katsiki, N., Panotopoulos, G., Franceschi, C., Benetos, A. and Mikhailidis, D.P. (2013) The Challenges of Moving from Ageing to Successful Longevity. Current Vascular Pharmacology, PMID, 24350930.

[3] Rizza, W., Veronese, N. and Fontana, L. (2014) What Are the Roles of Calorie Restriction and Diet Quality in Promoting Healthy Longevity? Ageing Research Reviews, 13, 38-45. http://dx.doi.org/10.1016/j.arr.2013.11.002

[4] van der Walt, A.M., Ibrahim, M.I., Benzuidenhout, C.C. and Loots, D.T. (2008) Linolenic Acid and Folate in WildGrowing African Dark Leafy Vegetables (Morogo). Public Health and Nutrition, 12, 525-530. http://dx.doi.org/10.1017/S1368980008002814

[5] Gqaza, M.B., Njume, C., Goduka, I.N. and Grace, G. (2013) Nutritional Assessment of Chenopodium album L. (Imbikicane) Young Shoots and Mature Plant-Leaves Consumed in the Eastern Cape Province of South Africa. International Proceedings of Chemical, Biological and Environmental Engineering, 53, 97-102.

[6] Singh, P.N., Sabate, J. and Fraser, G.E. (2003) Does Low Meat Consumption Increase Life Expectancy in Humans? The American Journal of Clinical Nutrition, 78, 526S-532S.

[7] Njume, C., Goduka, N.I. and George, G. (2014) Indigenous Leafy Vegetables (Imifino, Morogo, Muhuro) in South Africa: A Rich and Unexplored Source of Nutrients and Antioxidants. African Journal of Biotechnology. In press.

[8] Ebrahimzadeh, M.A., Nabavi, S.M., Nabavi, S.F., Bahramian, F. and Bekhradnia, A.R. (2010) Antioxidant and Free Radical Scavenging Activity of $H$. officinalis L. var Angustifolius, V. odorata, B. hyrcana and C. speciosum. Pakistan Journal of Pharmaceutical Sciences, 23, 29-34.

[9] Newman, A.B. and Brach, J.S. (2001) Gender Gap in Longevity and Disability in Older Persons. Epidemiologic Reviews. 23, 343-350. http://dx.doi.org/10.1093/oxfordjournals.epirev.a000810

[10] Bobak, M. (2003) Relative and Absolute Gender Gap in All-Caused Mortality in Europe and the Contribution of Smoking. European Journal of Epidemiology, 18, 15-18. http://dx.doi.org/10.1023/A:1022556718939

[11] Mansdotter, A. (2010) Further Thoughts on Gender and Life Time Health. Gerontology, 56, 345-347. http://dx.doi.org/10.1159/000274381 